East African Medical Journal Vol. 77 No. 9 September 2000

ISONIAZID PROPHYLAXIS FOR TUBERCULOSIS PREVENTION AMONG HIV INFECTED POLICE OFFICERS IN DAR ES SALAAM

M. Bakari, MD, MMed, Lecturer and Specialist Physician, A. Moshi, MD, MMed, Specialist Physician, E.A. Aris, MD, MMed, Specialist Physician, S. Chale, MD, MMed, Specialist Physician, R. Josiah, MD, MMed, Specialist Physician, P. Magao, MD, DPH, MSc, Trop. Med. Physician, TB Unit, Department of Internal Medicine, Muhimbili University College of Health Sciences, N. Pallangyo, MBChB, MMed, Medical Specialist, Kilwa Road Police Hospital, Dar es Salaam, F. Mugusi, MD, MMed, MSc, Senior Lecturer, Department of Internal Medicine, Muhimbili University College of Health Sciences, E. Sandström, Professor of Dermatovenereology, Department of Dermatovenereology, Soderjukhuset, Stockholm, Sweden, G. Biberfeld, Professor in Microbiology/Immunology, Swedish Institute for Infectious Disease Control and Karolinska Institute, Stockholm, Sweden, F. Mhalu, MBChB, FRCPath, Professor in Microbiology and Immunology, Dean Faculty of Medicine, Muhimbili University College of Health Sciences and K. Pallangyo, MD, MMed, Professor in Internal Medicine, Department of Internal Medicine, Muhimbili University College of Health Sciences, P.O. Box 65295, Dar es Salaam, Tanzania.

Request for reprints to: Dr. M. Bakari. Department of Internal Medicine, Muhimbili University College of Health Sciences, University of Dar es Salaam, P.O. Box 65295 Dar es Salaam, Tanzania.

\title{
ISONIAZID PROPHYLAXIS FOR TUBERCULOSIS PREVENTION AMONG HIV INFECTED POLICE OFFICERS IN DAR ES SALAAM
}

\author{
M. BAKARI, A. MOSHI, E.A. ARIS, S. CHALE, R. JOSIAH, P. MAGAO, N. PALLANGYO, F. MUGUSI, \\ E. SANDSTRÖM, G. BIBERFELD, F. MHALU and K. PALLANGYO
}

\begin{abstract}
Objective: To determine the acceptability, compliance and side effects of isoniazid (INH) prophylaxis against tuberculosis among HIV infected police officers (PO) in Dar es Salaam. Design: A nested study from a prospective follow up of a cohort of police officers.

Setting: Dar es Salaam, Tanzania.

Subjects: One hundred and forty three HIV-1 infected police officers.

Main outcome measures: Acceptance and compliance to INH prophylaxis.

Results: Of the 400 HIV-1 infected officers, $143(35.7 \%)$ came forward for post-test counselling and HIV test results. Sixty per cent $(87 / 143)$ of them accepted to be on INH prophylaxis. However only $42.5 \%$ (37/87) came forward for evaluation regarding their suitability for INH prophylaxis. During the evaluation, eight $(\mathbf{2 1 . 6 \%})$ of 37 otherwise asymptomatic PO were found to have active pulmonary tuberculosis (TB). Eventually only 29 PO were actually started on INH, and only $16(55.2 \%)$ of them completed the six months course. No serious side effects were observed. One PO developed TB two months after loss to follow up before completing the six months.

Conclusions: There was low acceptability of and poor compliance with INH prophylaxis among the HIV-1 infected PO despite being educated on the benefits of prophylaxis. The prevalence of PTB among asymptomatic HIV-1 infected PO was high, and therefore persons with HIV infection should be examined for TB even in the absence of symptoms.
\end{abstract}

\section{INTRODUCTION}

With the advent of potent anti-tuberculosis drugs more than three decades ago, it was hoped that tuberculosis (TB), the dreaded disease as old as man's history would soon cease to be a public health problem; but that has not happened. Until 1985 notified TB cases were decreasing, but since then the trend was reversed with HIV attributable TB cases ranging from $0-72 \%$ of reported TB cases between 1985 - 1993 in sub - Saharan Africa(1,2). It is estimated that the resurgence of TB would affect 90 million people by the year 2000(3).

In December 1998, the World Health Organisation estimated that 13.9 million people had died of AIDS since the beginning of the epidemic, more than 33 million were still infected and eleven new infections were occurring every minute(4). The HIV epidemic is particularly bad in sub-Saharan Africa, which accounts for more than two thirds of all infections in the world(5).

Data collected from antenatal clinics in Tanzania during 1998 showed that $12-20 \%$ and $11-24 \%$ of women attending rural and urban antenatal clinic centres respectively, were HIV infected(6). The prevalence of HIV antibodies among patients with clinical TB in Tanzania mainland ranged between 3 and 75.7\% during 1998 . Furthermore, the Tanzania National AIDS Control Programme (NACP) estimated that 140,000 new infections occurred in mainland Tanzania during 1998 alone(6). Consequently the pool of people with HIV infection is not only a big one but is increasing rapidly.

The risk of developing tuberculosis (TB) disease among HIV infected individuals and the association between tuberculosis and AIDS has been well documented. The incidence of tuberculosis in persons dually infected with HIV-1 and M. tuberculosis is about eight to fifteen per cent per year, representing a $30-50 \%$ or greater lifetime risk compared to ten per cent per lifetime in immune competent persons with positive tuberculin test $(3,7)$. Indeed, HIV infection is the strongest known risk factor for the development of tuberculosis(8). Active tuberculosis develops much early during the course of HIV infection and once it develops it accelerates the HIV disease progression(9). TB chemoprophylaxis for patients co-infected with HIV and M. tubeculosis is therefore of 
critical priority and has been recommended by the UNAIDS and $\mathrm{WHO}(10)$. Prophylaxis with isoniazid (INH) has been shown to reduce the incidence of TB in HIV infected persons either by eradicating latent infection and or preventing progression of new infection to active TB.

Whereas no drug toxicity from isoniazid was encountered in the Haitian study(11), in Spain(12) nine $(11 \%)$ of eighty six of patients had to discontinue therapy because of hepatotoxicity.

Adherence to tuberculosis preventive therapy among HIV infected persons is variable among different populations. In Thailand(14), it was reported to be $69.4 \%$. In a study conducted in Kampala, Uganda(15) high default rates occurred at all stages between presentation to the centre for voluntary counselling and provision of isoniazid to HIV positive persons with positive tuberculin tests in whom active disease had been excluded. In Mexico, Garcia and colleagues found compliance to be acceptable (90\%) and frequency of side effects to be low(16).

In order to provide preventive therapy in developing countries, there is need to address feasibility, sustainability, cost effectiveness, methods of delivery, and monitoring for exclusion of active tuberculosis, safety and adherence(17). In addition, regular evaluation of persons on preventive therapy is essential for detection of active tuberculosis, safety and adherence.

Beginning 1994, a cohort of consenting police officers in Dar es Salaam had been recruited to determine its suitability for HIV vaccine trial. Police officers who tested positive for HIV-1 antibodies were informed about their increased risk of developing clinical tuberculosis, at the time of giving the blood test results, and were invited to participate in the INH prophylaxis study.

The study received ethical clearance from the National AIDS Control Programme in the Ministry of Health, Dar es Salaam and the Karolinska Institute, Stockholm, Sweden.

The aims of the study were to determine the acccptability, compliance and side effects of INH prophylaxis among HIV-1 infected Police Officers in Dar es Salaam.

\section{MATERIALS AND METHODS}

This was a nested study from a cohort being prepared for possible HIV vaccine evaluation. At the beginning, all police officers from different stations in Dar es Salaam were informed about the study aims at their weekly meetings. Consenting officers were pre-test counselled for HIV blood testing. During post-test counselling visits, HIV -1 infected Police Officers were informed of their risk of developing active TB disease and potential benefits of isoniazid preventive therapy. Thereafter they were invited to participate in the INH prophylaxis study. Consenting officers were given an appointment to see one of the internist in the study at the Muhimbili Medical Centre, where participants were examined clinically and data was filled in a questionnaire. Laboratory evaluation included sputum smear for acid alcohol fast bacilli (AAFB), haemoglobin, white blood cell count, and erythrocyte sedimentation rate (ESR). Tuberculin skin test using two units Purified Protein Derivative (PPD) and a postero-anterior chest roentgenograph were done to all patients. A positive tuberculin reactivity was defined as an induration $\geq 5 \mathrm{~mm}(18)$. Diagnosis of active tuberculosis was based on positive sputum smears for AAFB. Patients with active TB were referred to $\mathrm{TB}$ treatment centres; those free from active TB were started on isoniazid $300 \mathrm{mg}$ once daily for a duration of six months.

These clients were followed up monthly until they completed the six months of treatment Thereafter they were followed up for two years. During the follow up visits, development of side effects was assessed based on history and physical examination. Compliance was assessed by pill counting and adherence rate was defined as taking more than $80 \%$ of the pills.

Data handling: Data were entered in a computer, analysis was done using EPI 6 software. Chi squared test was used to compare proportions and a $\mathrm{p}<0.05$ was considered significant.

\section{RESULTS}

General characteristics of study population: By the end of December 1998, two thousand eight hundred and ninety nine officers were enrolled in the main study, of these $2782(96 \%)$ accepted to be tested for HIV. Four hundred (14.4\%) were HIV-1 seropositive. The sociodemographic characteristics of the subjects has been reported elsewhere(19).

Isoniazid acceptability: Out of the $400 \mathrm{HIV}$ infected PO, $143(35.7 \%)$ came forward for post-test counselling. Among the counselled HIV seropositive PO, 87 (60.8\%) consented to take part in the isoniazid prophylaxis study; while $56(39.2 \%)$ refused (Table 1). Out of the 26 females who came forward for post-test counselling, 17 (65.4\%), consented for INH prophylaxis as compared to 59.8\% (70/ 117) male PO $(\mathrm{p}=0.599)$. The socio-demographic characteristics of PO consenting for INH and those declining are shown in Table 2 . The proportion of single PO in the consenting officers $(26.4 \%)$ was higher than among the declining officers, $(10.7 \%), p=0.02$. Significantly more extramarital sex was reported in the consenting PO as compared to the declining PO, $\mathrm{p}=0.007$.

Table 1

Acceptability if isoniazid prophylactic therapy among HIV seropositive police officers in Dar es Salaam

\begin{tabular}{|c|c|c|c|c|c|c|c|c|c|c|c|c|c|}
\hline & \multicolumn{2}{|c|}{ HIV+ ve } & \multicolumn{2}{|c|}{ Consented INH } & \multicolumn{2}{|c|}{$\begin{array}{l}\text { Initially screened } \\
\text { for active } \mathrm{TB}\end{array}$} & \multicolumn{2}{|c|}{$\begin{array}{l}\text { Found with } \\
\text { active TB }\end{array}$} & \multicolumn{2}{|c|}{ Started on INH } & \multicolumn{2}{|c|}{$\begin{array}{l}\text { Completed the } \\
\text { six months of } \\
\text { prophylaxis }\end{array}$} & Defaulted \\
\hline & $\mathrm{N}$ & $(\%)$ & $\mathrm{N}$ & $(\%)$ & $\mathrm{N}$ & $(\%)$ & $\mathrm{N}$ & $(\%)$ & $\mathrm{N}$ & $(\%)$ & $\mathrm{N}$ & $(\%)$ & $(\%)$ \\
\hline Male & 117 & $(76.5)$ & 70 & $(80.0)$ & 30 & $(81.1)$ & 6 & (75) & 24 & $(82.8)$ & 15 & $(78.9)$ & $9 \quad(90)$ \\
\hline Female & 26 & $(23.5)$ & 17 & $(20.0)$ & 7 & $(18.9)$ & 2 & (25) & 5 & $(17.2)$ & 4 & $(21.1)$ & $1 \quad(10)$ \\
\hline Total & 143 & $(100)$ & 87 & $(100)$ & 37 & $(100)$ & 8 & $(100)$ & 29 & $(100)$ & 19 & $(100)$ & $10(100)$ \\
\hline
\end{tabular}


Table 2

Socio-demographic characteristics among the isoniazid (INH)consenting and the INH-declining HIV seropositive police officers in Dar es Salaam

\begin{tabular}{|c|c|c|c|c|c|}
\hline & \multicolumn{2}{|c|}{ Consented to INH } & \multicolumn{2}{|c|}{ Declined INH } & \multirow[t]{2}{*}{ p-value } \\
\hline & $\mathrm{N}=87$ & $(\%)$ & $\mathrm{N}=56$ & $(\%)$ & \\
\hline Male & 70 & $(80.5)$ & 47 & (83.9) & 0.6 \\
\hline Female & 17 & (19.5) & 9 & (16.1) & 0.6 \\
\hline Mean age (SD) & 33 & $(6.2)$ & 33.9 & $(7.0)$ & 0.42 \\
\hline \multicolumn{6}{|l|}{ Marital status } \\
\hline Single & 23 & (26.4) & 6 & $(10.7)$ & 0.02 \\
\hline Married & 62 & (71.3) & 50 & (89.3) & 0.01 \\
\hline Other & 2 & $(2.3)$ & - & & \\
\hline Drinking alcohol & 57 & $(65.5)$ & 35 & $(62.5)$ & 0.7 \\
\hline $\begin{array}{l}\text { Extramarital sex } \\
\text { in the past } 3 \text { months }\end{array}$ & 28 & $(32.2)$ & 7 & $(12.5)$ & 0.007 \\
\hline $\begin{array}{l}\text { Condom use during } \\
\text { extramarital affair }\end{array}$ & 2 & $(2.3)$ & 7 & (12.5) & 0.035 \\
\hline
\end{tabular}

However, out of the eighty seven police officers consenting for prophylaxis with isoniazid, only 37 (42.5\%) eventually came forward to be evaluated for possible INH preventive therapy. The mean haemoglobin concentration among the study subjects was $12.97 \pm 1.76 \mathrm{~g} / \mathrm{dl}$; while the total white blood cells count was $5400 \pm 1497$ cells $/ \mathrm{mm}^{3}$. The mean erythrocyte sedimentation rate in the first hour was $45.4 \pm 30.9 \mathrm{~mm}$. Tuberculin skin test reactivity was $15.4 \%$ with a mean of $5.06 \pm 8.19 \mathrm{~mm}$. The Mean Body Mass Index was $18.6(2.9) \mathrm{kg} / \mathrm{m}^{2}$, and BCG scar was present in 19 officers, (17.1\%). Herpes zoster scar was present in three officers. Among the evaluated PO who were otherwise asymptomatic, eight (21.6\%) of the 37 officers were found to have active pulmonary tuberculosis as evidenced by positive sputum smears. The haematological indices on the evaluated PO showed no statistically significant differences between subjects found to have active TB and those without active disease.

Follow up and compliance: Twenty nine PO were started on isoniazid for prevention of TB. Out of these, only 19 officers (65.5\%), completed the prescribed six months course, and were fully compliant. Ten PO defaulted from INH prophylaxis (Table 1). One Police Officer did not come for follow up one month after enrolment and developed active TB a month later; while another PO developed active tuberculosis two years after completing the six months of INH prophylaxis

Side effects: No side effects were observed on all PO who were on preventive therapy and followed up for a mean duration of two years.

\section{DISCUSSION}

The study has shown that despite intense education on benefits of INH prophylaxis to HIV-1 infected police officers, its acceptability was disappointingly low. Low acceptability of INH among HIV infected has also been reported from Uganda at all levels of recruitment to INH preventive therapy(15). The low acceptability of INH in this cohort of PO may to some extent be due to fear of stigmatisation by peers or spouses if individuals are known to be HIV infected through regular medical appointments or regular use of medications as prolonged use of drugs is associated with chronic ill health, and this may be linked with HIV. Also the nature of police work is characterised by unexpected emergencies, and these could have hindered prospective HIV infected PO from showing up on the appointment dates for assessment regarding INH use.

The proportion of single PO who consented for INH prophylaxis was much higher than the declining ones. This is probably because when an individual is single, then he/she is not necessarily bound to reveal his/her HIV status to anyone, and will thus feel more free to consent and accept INH use. Similarly the proportion of INH declining PO was higher among the married police officers. Exposure or speculation about one's HIV status by a spouse in a married relationship can easily be linked to extramarital sexual affairs, a fact that may culminate in marital disharmony or even a divorce. The fact that a higher proportion of INH consenting PO reported extramarital sexual contacts perhaps reflects the boldness of these $\mathrm{PO}$ in being open regarding matters pertaining to their private lives such as sex and HIV disease. It is unlikely that effectiveness of counselling was a factor here, as in all instances the involved counsellors were physicians who were quite experienced in aspects of HIV and had undergone specific training in HIV counselling.

We found adherence rate to be $65.5 \%$. This is comparable to what was found in other studies in Uganda and Thailand where adherence rate was $69.4 \%$ and $62 \%$ in Thailand(14) and Uganda(15) respectively but it was much less than the $83.7 \%$ rate in the Mexican(16) study where home visits were accomplished on non attending subjects.

The number of active TB cases among asymptomatic HIV seropositive PO was high in this cohort. This could be attributable to immunosuppression by the HIV virus(20) and probably also by the socio-environmental factors like overcrowding in the police barracks as well as their places of work, which favour transmission of M. tuberculosis among the police. Observations in the National Tuberculosis Programme clinics reveal that the proportion of PO attending the various TB treatment centres in Dar es Salaam is higher than the general population (Personal communication). The finding of active TB in asymptomatic HIV infected PO is of immense public health importance as these cases will also pose a big threat to other workers and family members in terms of being infected with $M$. tuberculosis as reported previously $(20,21)$. Screening persons who are HIV seropositive for active TB even in the absence of symptoms will thus identify the cases for treatment and hence optimise TB control; and for those cured of TB delay progression of their HIV disease.

There was no serious untoward effects observed in these subjects put on INH prophylaxis, a finding similar to the Haitian study(11). 
One case of active TB developed two years after completing the six months of INH prophylaxis. This may imply that six months of INH prophylaxis is inadequate for preventive therapy and therefore, poses a crucial question as to how long should the INH prophylaxis be given in HIV infected individuals living in an area highly endemic for tuberculosis. Life-long prophylaxis seems more appropriate. Clearly more studies are required to resolve this issue.

Tuberculin skin reactivity was low in this group of patients, however, INH prophylaxis was offered to all consenting HIV infected PO with no active TB regardless of their tuberculin skin reactivity since it is presumed that more than $80 \%$ of our general population is known to be primarily infected with $M$. tuberculosis(6). This is especially important when the reactivity to other recall antigens was not done, and that immune suppression by HIV could have affected tuberculin reactivity.

In conclusion, there was low acceptability of INH prophylaxis among the HIV-1 infected officers despite being educated on the importance of INH prophylaxis. It follows that the operational aspect of providing INH prophylaxis in HIV infected individual calls for extreme care, vigilance and far more efforts than one may expect including consideration to undertake home visiting for those declining participation. The high prevalence of PTB among asymptomatic HIV seropositive PO also stresses the importance of actively searching for tuberculosis in all HIV infected individuals, even if asymptomatic, especially in communities where both HIV and tuberculosis co-exist. Further studies are needed to address important questions of reasons for low acceptability; and optimal duration of INH prophylaxis among HIV infected patients.

\section{ACKNOWLEDGEMENTS}

This work was funded by the (SIDA - SAREC) TANSWED HIV PROGRAM. The study was given institutional ethical clearance from the National AIDS Control Program in the Ministry of Health, Dar es Salaam and the Karolinska Institute, Stockholm, Sweden.

\section{REFERENCES}

1. Cantwell M.F. and Binkin N.J. Impact of HIV on tuberculosis in sub-Saharan Africa: a regional perspective. Int. J. tuberc. Lung. Dis. 1997; 1: 205-14

2. Cantwell M.F. and Binkin N.J. Tuberculosis in sub-Saharan Africa: regional assessment of the impact of the human immunedeficiency virus and National Tuberculosis Control Program quality. Tuber. Lung. Dis, 1996; 77: 220-5.

3. Narain J.P., Raviglione M.C. and Kochi A. HIV associated tuberculosis in developing countries: epidemiology and strategies for prevention. Tuber. Lung Dis 1992; 73:11-21 .

4. UNAIDS/WHO AIDS epidemic update December 1998: 1-16

5. Graham B.S. Infection with HIV- 1. Brit. Med. J. 1998;317:12971301.
6. Ministry of Health Tanzania Mainland National AIDS control Programme HIV/AIDS/STDs Surveillance Report No. 13, December, 1998.

7. Wadhawan D., Hira S., Mwansa N., SLnkutu K., Adera P. and Perine P. Preventive tuberculosis chemotherapy with Isoniazid INH among patients infected with HIV-1. Ninth International Conference on AIDS in affiliation with the Fourth STD World Congress, Berlin, June 6-11, 1993: abstr PO-B07 - 1114.

8. Murray J.F. The White Plague: down and out, or up and coming? Amer. Rev. Respir. Dis. 1989; 140: 1788-95.

9. Whalen C., Horsburgh C.R., Hom D., Lahart C., Simberfkoff M. and Ellner J. Accelerated course of human immunedeficiency virus infection after tuberculosis. Amer. J. Respir. Crit. Care Med. 1995; 151: 129- 135.

10. WHO and UNAIDS. Policy statement on preventive therapy against tuberculosis in people living with HIV. WHO $1998 \mathrm{WHO} /$ TB/98:225.

11. Pape J.W., Jean S.S., Ho J.L., Hafner A. and Johnson W.D. Jr. Effect of INH prophylaxis on incidence of active tuberculosis and progression of HIV infection. Lancet 1993; 342: 268-72.

12. Guelar A., Gatell J.M. and Podzamczer D. et al. A Prospective Study of the risk of tuberculosis among HIV-infected patients. AIDS 1993; 7: 1345-49.

13. Selwyn P.A., Sckell B.M., Alcabes P., Friedland G.H., Klein R.S. and Schoenbaum E.E. High risk of active tuberculosis in HIV infected drug users with cutaneous energy. J. Amer. Med. Ass. 1992; 268:504 - 09.

14. Ngamvithayapong J., Uthaivoravit W., Yanai H., Akarasewi P. and Sawanpanyalert P. Adherence to tuberculosis preventive therapy among HIV infected persons in Chiang Rai, Thailand. AIDS 1997; 11: 107-112.

15. Aisu T., Aisu T., Raviglione M.C. and Van Praag E. et al. Preventive chemotherapy for HIV associated tuberculosis in Uganda: an operational assessment at voluntary counselling and testing centre. AIDS 1995; 9: 267-73

16. Garcia M.L., Valdespino J.L., Garcia-Sancho C., Weissenbacher M., Daniels E., Peruga A., Palacios M., Loo E., Cruz C., Luna J.L. et al. Int. Conf AIDS 9(1): 324 (Abstract No. PO-BO7 - 1133) 1993 JUN 6-11

17. De Cock K.M., Grant A. and Porter J.D.H. Preventive Therapy for Tuberculosis in HIV-1 infected persons: international recommendations, research, and practice. Lancet 1995; 345:833836.

18. World Health Organization. II. State- of- the - Art Summaries. WHO/TUB/GPA 92.1;2-11.

19. Bakari M., Lyamuya E., Mugusi F., Aris E., Chale S., Magao P., Josiah R., Janabi M., Swai A., Pallangyo N., Sanstrom E., Mhalu F., Biberfeld G. and Pallangyo K. The prevalence and incidence of HIV- 1 infection and syphilis in a cohort of police officers in Dar es salaam, Tanzania; a potential population for HIV vaccine trials. AIDS 2000, 14:1-8

20. Daley C.L., Small P.M. and Schecter G.F., et al. An outbreak of tuberculosis with accelerated progression among persons infected with HIV. N. Engl. J Med 1992; 326: 231 - 235.

21. Selwyn P.A., Hartel D., Lewis V.A., et al. A prospective study of the risk of tuberculosis among intravenous drug users with human immunedeficiency virus infection. N. Engl. J. Med. 1989;320:545 -550 . 